\title{
LA RESPUESTA A LOS PELIGROS NATURALES Y AL CAMBIO CLIMÁTICO EN EUROPA
}

\author{
Schmidt-Thomé, Philipp (GTK, Finland) ${ }^{1}$ \\ Greiving, Stefan (IRPUD, Dormund University) ${ }^{2}$ \\ ${ }^{1}$ Geological Survey of Finland (University of Bonn) \\ ${ }^{2}$ Institut of SpatialPlanning (University of Dortmund)
}

\section{RESUMEN}

Los peligros naturales son la causa de desastres terribles y también la fuente de importantes ventajas naturales, por lo que desempeñan un papel crucial al crear tanto restricciones como oportunidades para el desarrollo territorial. Por lo pronto, si la comparamos con el resto del mundo, probablemente Europa no sea propensa a sufrir los efectos más catastróficos de los desastres, aunque este continente está afectado por algunos de los más considerables. En el presente estudio, se analizan los riesgos resultantes, incluidos los efectos potenciales del cambio climático en toda Europa, con el objeto de crear medidas adecuadas para sostener el desarrollo territorial. La ordenación territorial constituye un elemento destacado en la gestión de los riesgos y de las repercusiones del cambio climático. La creciente importancia de los peligros naturales en el entorno vital ha provocado un aumento de las prácticas nacionales de ordenación territorial en las últimas décadas y, en la actualidad, también centra la atención de la Unión Europea. Aquí examinamos una incorporación más sólida de los peligros, los impactos del cambio climático y los riesgos resultantes en la ordenación territorial y en la gestión pública de los riesgos en el ámbito nacional y local y además esbozamos propuestas para el ámbito europeo.

Palabras clave: Peligros naturales, cambio climático, ordenación del territorio, gestión del riego.

\section{ABSTRACT}

Natural hazards are the cause for terrible disasters, but also the source of important natural advantages, and thus they play a vital role in creating both restrictions and potentials of territorial development. Meanwhile Europe, as compared to the rest of the

1 E-mail: philipp.schmidt-thome@gtk.fi. Internet: www.gtk.fi.

2 E-mail: stefan.greiving@uni-dortmund.de 
world, is arguably not prone to the most catastrophic effects of disasters, but this continent is nevertheless affected by several of the most important natural hazards. The resulting risks, including the potential effects of climate change, are analyzed on European scale with the aim to develop appropriate measures to support territorial development. Spatial planning plays an important role in the management of hazards and climate change impacts. The growing importance of natural hazards on the living environment has caused an increase of related national planning practices in European states in the past decades, and is now also receiving attention from the European Union. A stronger incorporation of hazards, climate change impacts and the resulting risks into spatial planning and risk governance is here analyzed on local and national scale and proposals are outlined for the European scale.

Key words: Natural hazards, climate change, spatial planning, risk governance.

\section{Introducción}

El territorio europeo se ve afectado por una amplia gama de peligros naturales (SchmidtThomé y Kallio 2006). Aunque los daños y las pérdidas causados por los peligros naturales no sean tan catastróficos como en otras regiones del mundo (EM Dat 2006), los peligros naturales influyen en las oportunidades para el desarrollo regional en Europa. Los daños causados pueden provocar pérdidas financieras sustanciales debido a la alta densidad de la población, de las superficies edificadas y de las infraestructuras en la Unión Europea.

Los efectos potenciales del cambio climático en los riesgos hidrometeorológicos indican que determinadas regiones podrán experimentar un aumento en la frecuencia de algunos peligros naturales en los próximos 100 años (Bärring y Persson 2006, Schellnhuber et al. 2006). Las reacciones a esta situación se producen no sólo bajo la forma de una creciente relevancia de los peligros naturales y riesgos relacionados en algunos sistemas de ordenación europeos (por ejemplo, Fleischhauer et al. 2006), sino también en la estrategia de la Comisión Europea que ha propuesto que se preste más atención a los riesgos en la próxima ronda de solicitudes para el Fondo Europeo de Desarrollo Regional (Comisión Europea 2004, 2006).

El presente estudio analiza la dimensión espacial y los efectos de los peligros naturales en Europa y arroja luz sobre la posible influencia del cambio climático. Se debaten las nociones de vulnerabilidad y riesgo y su aplicabilidad a la ordenación territorial. Además, se examinan las estrategias actuales nacionales para la mitigación y adaptación a los peligros en Europa y otras propuestas, como en el ámbito de la gestión pública de los riesgos. Por último, se estudian los resultados y otras aplicaciones de una primera estrategia de cartografía de peligros y riesgos para toda la UE.

La visión general sobre el alcance y los efectos de los peligros naturales en Europa que presentamos aquí se basa, principalmente, en los hallazgos del Proyecto ESPON 1.3.1 (Schmidt-Thomé y Kallio 2006). Este proyecto, también denominado «Proyecto ESPON sobre Peligros», ha producido una primera estrategia integrada para trazar un mapa de todos los peligros relevantes para la ordenación territorial que cubre casi todo el continente europeo. Dado que se trata del primer proyecto para realizar la topografía de todos los peligros en la misma escala, empleando conjuntos de datos comparables con la misma cobertura geográfica, los resultados todavía son preliminares. A la hora de examinar los datos, hay que recordar siempre que muestran la distribución y la intensidad de los peligros desde una perspectiva europea. La tarea de fondo del proyecto estaba determinada por la necesidad de obtener información sobre los peligros naturales que 
afectan al desarrollo regional en Europa. Debido a que, hasta ahora, no existía ningún proyecto europeo de investigación que hubiera producido resultados que abarcaran todo el territorio, persistía la necesidad de realizar una panorámica que ha dado lugar a este planteamiento, en parte sintético.

A fin de determinar la importancia de los peligros naturales desde una perspectiva europea, el proyecto ESPON sobre Peligros llevó a cabo un proceso de ponderación, el llamado método Delphi (Schmidt-Thomé y Kallio 2006, Olfert et al. 2006). Este proceso fue utilizado, principalmente, para elaborar mapas de peligros y riesgos totales para Europa, pero también resulta valioso para analizar la importancia de los peligros y riesgos desde una amplia gama de perspectivas continentales y locales. Asimismo, debido a la falta de comparabilidad de las clases de peligros en una escala común, se empleó el sistema de ponderación en el proceso de agregación de los peligros. Según el método Delphi, los peligros naturales más destacados de Europa son las inundaciones, seguidas de los incendios forestales y los terremotos. Por supuesto, lo anterior es válido sólo desde una perspectiva europea. Si nos fijamos en el ámbito local, la información se vuelve imprecisa, por lo que no se recomienda. A modo de ejemplo, Schmidt-Thomé et al. (2006) han estudiado los resultados obtenidos en el proyecto ESPON sobre peligros en el ámbito nacional finlandés. Efectivamente, el peso dado a los peligros se aleja en gran medida de los resultados vistos desde el punto de vista europeo. Según los resultados del Proyecto ESPON sobre Peligros, Finlandia parece un país que no está expuesto a peligros considerables. Sin embargo, la realidad es muy distinta, ya que las inundaciones en Finlandia son notables y también ocupan su lugar en las prácticas de ordenación territorial (por ejemplo, Jarva y Virkki 2006). El motivo de que no figuren en los mapas de ESPON estriba en el hecho de que no se produjeron grandes inundaciones durante el periodo de observación y en que las inundaciones finlandesas suelen tener magnitudes menores (con menos víctimas mortales) que las de otras regiones europeas. Naturalmente, se puede aducir que, desde una perspectiva mundial, el continente europeo está bendecido, en general, con pocos peligros naturales puesto que los principales desastres rara vez tienen lugar en él. No obstante, siempre hay que examinar la relevancia regional y local de los peligros en una escala adecuada a fin de determinar las repercusiones, por ejemplo, en la economía local (por ejemplo, Schmidt-Thomé 2006).

Es necesario fomentar la gestión pública de los riesgos, tanto en el ámbito local como en el europeo. Esta necesidad se debe a que los crecientes costes de los peligros naturales, incluidos los efectos del cambio climático, exigen una mejor gestión de los riesgos en todos los niveles de las políticas. Damos algunos ejemplos de toma de decisiones local que están tomados de proyectos cofundados con la iniciativa INTERREG IIIB en la región del mar Báltico. Estos proyectos facilitaron la participación de las partes interesadas, lo cual derivó en una toma de decisiones sobre la utilización futura del territorio basada en las repercusiones del cambio climático en la subida del nivel del mar, las inundaciones y otros peligros naturales.

\section{Los peligros naturales que afectan al territorio europeo}

El territorio europeo no se ve afectado por igual por los peligros naturales puesto que su diversidad natural, meteorológica y geológica da lugar a patrones de peligros característicos por regiones. Los peligros sísmicos, como los volcanes, además de las sequías y los incendios forestales, se concentran principalmente en las zonas del Mediterráneo y en algunas líneas de fallas, así como en territorios de ultramar de la UE. Asimismo, hay un alto potencial de sequías e incendios forestales en el centro, sur y este de Europa. Por otro lado, las tormentas y las mareas de temporales están restringidas, sobre todo, a las zonas 
costeras y a las regiones de interior y son más inminentes, desde el punto de vista climático, a lo largo de la costa del mar del Norte y del mar Báltico que en los demás lugares de Europa. Las inundaciones se producen a lo largo de la mayoría de los ríos principales y se concentran principalmente en Europa central y oriental. Las avenidas torrenciales y los desprendimientos de tierras suelen ocurrir en las zonas montañosas y las avalanchas en las zonas montañosas nevadas de tipo alpino. No obstante, los peligros locales pueden desempeñar un papel importante fuera de las regiones citadas (Schmidt-Thomé y Kallio 2006).

Al debatir las estrategias de mitigación de los peligros naturales, se ha producido un cambio de paradigma: se ha pasado de las soluciones puramente tecnológicas, como diques para la protección frente a inundaciones, a la adaptación a los peligros (por ejemplo, Oficina Federal del Desarrollo Territorial 2006). Como no se pueden mitigar completamente los peligros naturales, el objetivo de la mitigación también incluye el ajuste de las formas de explotación del suelo, es decir crear espacio para los desastres naturales. Pero no todos los peligros naturales tienen una «relevancia espacial», o dicho de otro modo, no todos pueden ser mitigados con políticas de ordenación territorial. Por lo tanto, Fleischhauer (2006) emplea planes de riesgos desarrollados por el Consejo Asesor Alemán (WBGU 1999) para crear un filtro especial que permita la identificación de los peligros naturales relevantes para el espacio. Anteriormente hemos presentado el alcance y los efectos de esos peligros naturales en el territorio europeo. A continuación, analizaremos algunos de los peligros naturales más decisivos para la economía que se dan en Europa. En la tabla 1 se resumen los efectos de otros peligros naturales. Para obtener un análisis más detallado véase Schmidt-Thomé y Kallio (2006). En el informe definitivo del proyecto (SchmidtThomé (ed.) 2005) y en una colección de artículos publicada por la Inspección Geológica de Finlandia (Schmidt-Thomé (ed.) 2006(2)) se examinan exhaustivamente los resultados del proyecto ESPON sobre Peligros.

Las inundaciones fluviales surgieron como un desafío creciente al entorno construido en cuanto el ser humano empezó a intervenir para cambiar, enderezar e incluso reubicar lechos de los ríos con sus zonas naturalmente propensas a inundaciones, al mismo tiempo que se asentaba en zonas de baja altitud cercanas a los ríos. El aumento del sellado del suelo también produce un mayor nivel de peligro de inundaciones, dado que las aguas pluviales discurren directamente hacia los arroyos y la retención natural de la tierra ya no retrasa el flujo de masa de agua hacia los ríos. Se considera que las inundaciones constituyen el peligro natural más significativo en Europa. El mayor número de inundaciones graves entre 1987 y 2002 se concentró en el noroeste de Rumania, el sudeste de Francia, el centro y sur de Alemania y el este de Inglaterra (Schmidt-Thomé y Kallio 2006).

La elaboración del mapa originó varios debates debido a que existían fuertes presiones para medir la magnitud de las inundaciones y no su recurrencia. Se constató que el debate se debía a intereses políticos, ya que, por ejemplo, la relativamente elevada cantidad de inundaciones en Europa oriental representada en el mapa tampoco obtuvo una buena acogida. Resulta evidente que la intención era demostrar el alto riesgo de inundaciones en los países del centro y del oeste. Se obtuvieron experiencias similares con otros mapas durante el proyecto ESPON sobre Peligros. La sequía de 2003 en Europa representó casi una tercera parte de las pérdidas económicas debidas a peligros naturales (Compañía Reaseguradora de Munich 2004). Naturalmente, las sequías afectan con más fuerza a las regiones mediterráneas debido a los veranos calurosos y secos, pero también ha de tenerse en cuenta que los efectos de la sequía creada por el hombre son considerables. Existen varios ejemplos de mala gestión de los recursos hídricos en relación con, por ejemplo, la sobreexplotación de los acuíferos, el sellado de las superficies, las escorrentías y el recambio restringido de las aguas continentales, el uso excesivo del agua en las zonas áridas y la agricultura intensiva. 


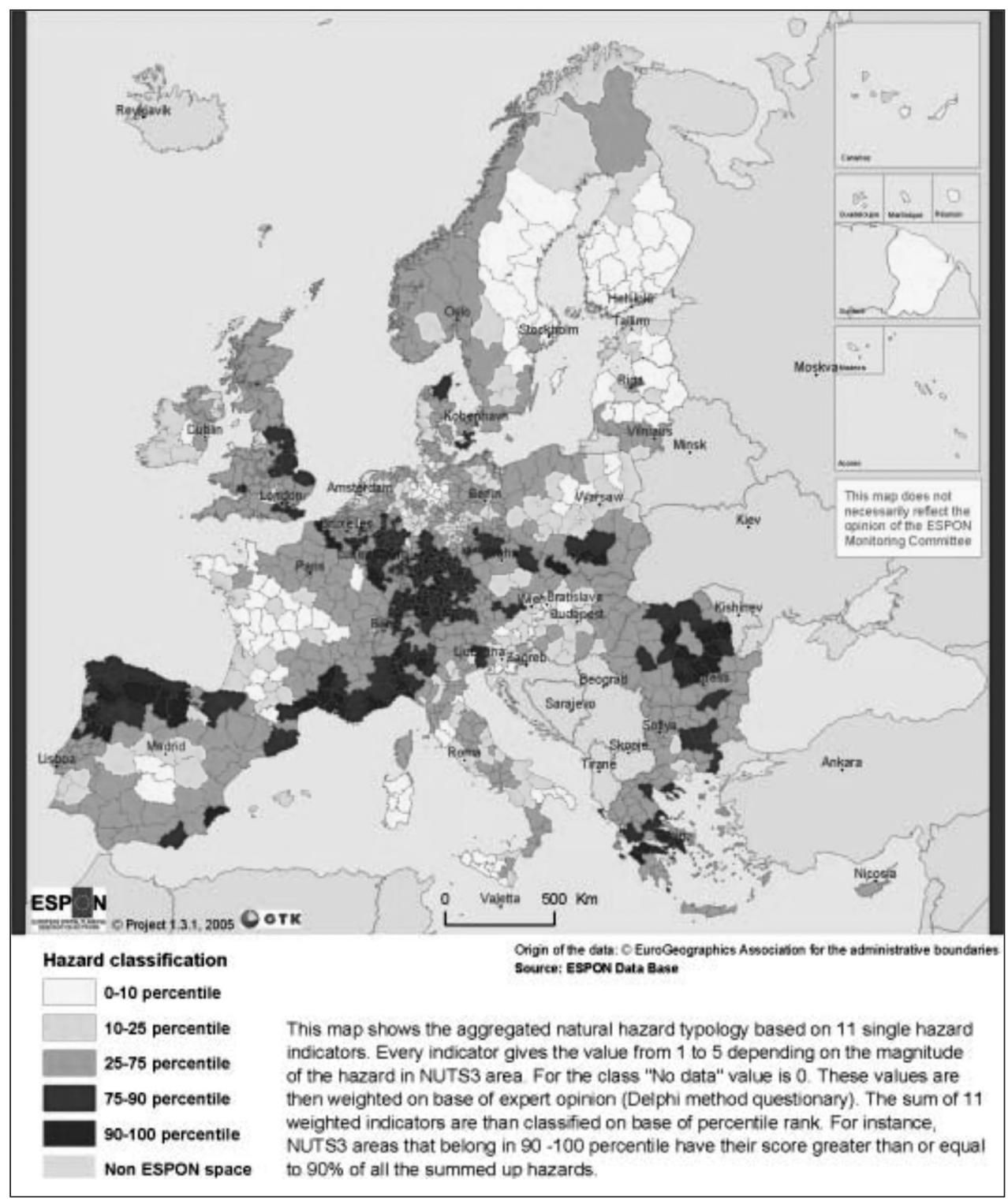

MAPA 1. Peligros naturales agregados en Europa (Schmidt-Thomé y Kallio 2006).

Los países del este de Europa, aparte de haber experimentado varias inundaciones en los últimos quince años, también sufren problemas graves con las sequías desde hace cien años (Schmidt-Thomé y Kallio 2006).

Los incendios forestales (fuegos descontrolados) pueden causar daños considerables para el medio ambiente. En general, se trata de fenómenos naturales que tienen su importancia 
para la regeneración natural de los bosques porque actúan como un proceso de limpieza. El potencial más grande se presenta en las regiones del Mediterráneo y, en parte, también en Rumania y Bulgaria. El alto riesgo de incendios forestales en el centro y norte de Portugal y en el noroeste de España está relacionado con las costumbres locales de «cortar y quemar», unas prácticas que son peligrosas, sobre todo, cuando ya existe un alto potencial de incendios forestales.

En términos generales, los peligros naturales ponen en riesgo a los seres humanos y a los bienes, mientras que la naturaleza y los ecosistemas siempre se han adaptado a los desastres naturales (por ejemplo, Schmidt-Thomé 2006). Los peligros naturales pueden crearse por las actividades humanas y representar así una cierta amenaza a los ecosistemas, por lo menos desde el punto de vista humano. El riesgo es una función de un peligro (o de muchos peligros) y de la vulnerabilidad. Dicho de otro modo, el riesgo depende de la intensidad del peligro y del alcance potencial de los daños desde la perspectiva humana. El desafío clave consiste en controlar o influir en la fuerza motriz que se encuentra tras el riesgo. El crecimiento económico y la concentración de la población en las zonas amenazadas provocan una mayor vulnerabilidad, incluso si los peligros no suceden con mayor frecuencia que antes. Esta combinación de factores naturales y creados por el hombre constituye la causa principal del rápido aumento de las pérdidas originadas por los desastres naturales en Europa.

Tabla 1

EFECTOS CONOCIDOS DE UNA SELECCIÓN DE LOS MAYORES DESASTRES NATURALES EN LOS PAÍSES EUROPEOS (1970-2005)

\begin{tabular}{|l|r|r|r|}
\hline \multicolumn{1}{|c|}{$\begin{array}{c}\text { Tipo de desastre } \\
\text { natural }\end{array}$} & \multicolumn{1}{c|}{$\begin{array}{c}\text { Número de } \\
\text { desastres }\end{array}$} & \multicolumn{1}{c|}{ Muertes } & \multicolumn{1}{c|}{$\begin{array}{c}\text { Estimación del coste de } \\
\text { los daños (x1.000 €) }\end{array}$} \\
\hline Inundaciones & 274 & 3.270 & 53.577 .458 \\
\hline Tormentas & 215 & 1546 & 34.403 .573 \\
\hline Terremotos & 123 & 19.644 & 43.936 .462 \\
\hline Temperaturas extremas & 69 & 47.466 & 1.889 .329 \\
\hline Incendios forestales & 63 & 248 & 2.471 .668 \\
\hline Deslizamientos & 46 & 1314 & 1.023 .464 \\
\hline Sequías & 26 & 0 & 12.989 .281 \\
\hline Erupciones volcánicas & 7 & 9 & 36.769 \\
\hline Total & 823 & 73.497 & 150.328 .003 \\
\hline
\end{tabular}

* En la base de datos de desastres EM-DAT sólo se registran los desastres con los siguientes criterios mínimos: (a) al menos 10 personas perdieron la vida, (b) al menos 100 personas se vieron afectadas, (c) declaración de estado de emergencia, (d) llamamiento a la ayuda internacional. (Fuente: EMDAT, 2006).

La presión de una población en aumento y el incremento del PIB, junto con el efecto de la demanda relacionada de espacio, también ponen a prueba la sostenibilidad de las zonas costeras, marítimas, cuencas fluviales y montañosas. Por ejemplo, las zonas costeras se enfrentan a un índice extremo de sellado del suelo debido al crecimiento urbanístico, sobre todo, aunque no de forma exclusiva, en la zona del Mediterráneo. Las cuencas fluviales 
también experimentan el desarrollo urbanístico y el sellado del suelo, además de la fragmentación. Los ecosistemas de las montañas no sólo sufren por el crecimiento urbanístico, sino también por el aumento de las actividades recreativas.

\section{El cambio climático y sus efectos en los peligros naturales}

Se prevé que el cambio climático origine cambios en variables climatológicas, como las temperaturas medias y extremas, las precipitaciones (incluidas las nevadas y heladas) y el viento. Si se tiene cuenta el cambio de la duración de los periodos secos, las zonas más meridionales de Europa afrontan el mayor aumento de peligros naturales desencadenados por el cambio climático. Es posible que un cambio en las pautas del viento o un incremento de sucesos extremos dé lugar a un nivel considerablemente mayor de peligro por las tormentas de invierno (por ejemplo, Bärring y Persson 2006). Entre los ejemplos de sucesos extremos se encuentran las tormentas de invierno «Gudrun» en la región del mar Báltico en 2005 y «Kyrill» en el norte de Europa en 2007, los veranos extremadamente secos y las olas de calor de 2003 y 2006, las tremendas inundaciones en el centro y el este de Europa en 2002 y 2005, así como los incendios forestales que azotaron la península Ibérica a principios del siglo XXI. Además, las consecuencias del aumento de las precipitaciones en los corrimientos de tierras y avalanchas tendrán efectos más visibles en el ámbito local.

Si bien en Europa no se incorporó el cambio climático a la ordenación territorial hasta hace poco, ahora su importancia no deja de aumentar, por ejemplo en la Agenda territorial de la Unión Europea (2007). En el Reino Unido, el término «sostenible» fue integrado en la ordenación territorial durante la década de los noventa (Bulkeley 2006) y el cambio climático forma parte de la ordenación mediante estrategias de mitigación, es decir, con la atención puesta en la reducción de las emisiones de gases de efecto invernadero y, de forma más específica, en la función que desempeña el tráfico (Robinson 2006, Levett 2006). En los Países Bajos, la atención se ha desplazado de las estrategias de mitigación a las de adaptación (Vries 2006). Existen varias estrategias nacionales y llamamientos para integrar el cambio climático y, además, las ciudades o las regiones han empezado a emprender iniciativas (por ejemplo, Marttila et al. 2005, Reino Unido 2006). En Finlandia, Peltonen et al. (2005) proponen una serie de recomendaciones para integrar la adaptación a la ordenación urbanística. De hecho, Finlandia ya ha pasado de una estrategia nacional de adaptación al cambio climático a un programa sobre cambio climático para el periodo de 2006 a 2010 (http://www.mmm.fi/ - actualmente sólo disponible en finés). Alemania ha acordado El nuevo programa nacional sobre cambio climático (2005). Como en otros Estados, dejando de lado las acciones de mitigación, se ha prestado más atención a la adaptación. Aun así, en este contexto, la ordenación territorial no ha recibido ninguna mención especial.

Puede utilizarse la cartografía de los peligros naturales en el ámbito europeo, por ejemplo, para distribuir los Fondos Europeos de Desarrollo Regional (Schmidt-Thomé y Schmidt- Thomé 2006). Sin embargo, deben tenerse en cuenta las limitaciones de la escala, la resolución y los conjuntos de datos subyacentes. Por lo tanto, las estrategias de mitigación y adaptación a los peligros requieren siempre unas evaluaciones locales (por ejemplo, Schmidt-Thomé 2006).

En la siguiente sección resumimos las estrategias relacionadas de los Estados europeos que, potencialmente, podrían aplicarse en toda Europa. Es evidente que esas estrategias precisan modificaciones y una mayor investigación antes de su aplicación en el ámbito europeo y que muchas de ellas ni siquiera han sido aplicadas plenamente en el ámbito nacional. No obstante, las tendencias actuales del aumento de costes debido a los peligros 
naturales demuestran que la importancia de tales iniciativas va en aumento. Más adelante, presentamos algunos ejemplos de aplicaciones prácticas de la información sobre peligros naturales y cambio climático en relación con la ordenación territorial, tanto en el ámbito europeo como en el local.

\section{Estrategias para las políticas y la gestión pública europeas de los riesgos}

La gestión de los riesgos debería ser una parte integrante y explícita de la Política de Cohesión de la UE, dado que los análisis demuestran hasta qué punto los peligros son omnipresentes en el territorio de la UE. Esta circunstancia requiere una mejor coordinación en todos los ámbitos que incumben al territorio.

El énfasis en la reducción de la vulnerabilidad constituye una estrategia clave. Debe reconocerse que la vulnerabilidad afecta a las repercusiones de los riesgos, tanto para el ser humano como para la sociedad, incluidos sus patrones espaciales.

El objetivo debe ser una forma de desarrollo policéntrico. Un elemento clave de la Perspectiva de Desarrollo Territorial Europeo ((ESDP, 1999) consiste en equilibrar los patrones de vulnerabilidad en Europa. Es necesario asegurarse de que se tienen en cuenta todos los aspectos de la vulnerabilidad (económicos, sociales y ecológicos) al contemplarlos en los análisis de vulnerabilidad integrada. Deben incluirse tanto los objetivos sustantivos como las normas procedimentales en relación con la reducción de la vulnerabilidad y la gestión de riesgos.

Lo que se necesita es que las partes interesadas recurran a estrategias de adaptación. El triángulo «resistencia - resiliencia - retirada» debe formar parte de los debates sobre medidas políticas (Greiving 2006a).

- Resistencia: protección contra (todos) los riesgos mediante medidas estructurales.

- Resiliencia: minimización del riesgo para la vida y las propiedades cuando se produce un suceso de riesgo.

- Retirada: abandono de las zonas peligrosas.

Los tres elementos principales de una estrategia de gestión de riesgos concebida en función de la retirada son, en concreto:

- Mantener las zonas amenazadas libres de más usos del suelo vulnerables mediante calificaciones adecuadas realizadas por las autoridades competentes (por ejemplo, gestión de aguas y/u ordenación territorial).

- Reasignación de los usos del suelo existentes lejos de las zonas amenazadas (programa de calificaciones + financiación/compensación para los propietarios de los terrenos).

- Los dos elementos pueden combinarse con la extensión de la zona de retención (reasignación de los diques, pozos de retención) en caso de inundación u otras medidas similares, como bosques protectores en caso de peligro de avalancha, etc.

Las dos opciones exigen una evaluación de los riesgos bien preparada ante la necesidad de intervenir en propiedades privadas. Esta decisión depende no sólo de la intensidad del peligro (función del periodo de recurrencia y la magnitud), sino también de la vulnerabilidad de un determinado uso del suelo y de la capacidad de reajuste de la comunidad afectada. Lo anterior significa que la reasignación será conveniente sólo para aquellos usos del suelo, como zonas industriales, infraestructuras públicas, etc., que son especialmente 
vulnerables. Los tres elementos (resistencia, resiliencia y retirada) pueden combinarse en la misma zona para usos distintos del suelo. También puede resultar adecuado concentrarse en elementos diferentes para la misma categoría de uso del suelo en zonas distintas ante un riesgo determinado. Elegir una estrategia de respuesta adecuada frente a los riesgos de inundaciones depende del nivel de riesgo que la sociedad esté dispuesta a tolerar, pero también de la naturaleza de los distintos usos del suelo y, por lo tanto, constituye una cuestión normativa. Además, se necesita una cuestión normativa respecto al tipo de acción de mitigación, lo cual requiere una evaluación del riesgo de que se trate que examine detenidamente la vulnerabilidad del sistema afectado y también los intereses de la población afectada (la gestión pública de los riesgos debe ser considerada como parte integrante de la gestión pública como estrategia general para la creación de políticas en el siglo XXI, véase la siguiente sección con un análisis más detallado). En este contexto, un periodo de recurrencia, como 100 años para las inundaciones en toda Europa o incluso para una cuenca hidrográfica, no puede constituir la base común para semejantes decisiones. Además, con el cambio climático, es posible que el periodo de recurrencia de un fenómeno determinado cambie en el futuro.

\section{El fomento de la gestión transeuropea tecnológica y de riesgos naturales}

Los peligros naturales plantean riesgos para los seres humanos y los sistemas socioeconómicos, que se producen cuando los asentamientos o las infraestructuras se sitúan en zonas naturalmente peligrosas. En Europa esto sucede con frecuencia. Como no se pueden mitigar totalmente los peligros naturales, la estrategia más adecuada consiste en reducir la vulnerabilidad. Este proceso ha empezado en algunas regiones, pero todavía falta una estrategia europea, o un proceso de adaptación general, que incluya los efectos del cambio climático en los peligros naturales. Aunque el territorio europeo como tal no está demasiado amenazado por peligros naturales, su diversidad natural, meteorológica y geológica provoca patrones característicos por regiones (véase el mapa 1 anterior). Estos patrones específicos de peligros naturales originan patrones específicos de riesgos, cuyo tratamiento más adecuado es la mitigación regional y, mejor aún, los procesos de adaptación.

Debido a que los peligros y los riesgos están distribuidos de forma desigual, se recomienda establecer prioridades para la evaluación de los riesgos del territorio. Esas prioridades deben centrarse en el impacto para el desarrollo territorial de todos los peligros potenciales correspondientes a la región. Dado que algunos peligros, a pesar de que no sean evidentes desde el punto de vista europeo, pueden ser relevantes desde el punto de vista local, esas prioridades deben dar cabida a evaluaciones locales específicas para el territorio.

Dicho de otro modo, el riesgo que una región está dispuesta a asumir desempeña un papel crucial en el debate sobre vulnerabilidad. Los asentamientos no deben ser eliminados de las zonas naturalmente peligrosas y tampoco puede pararse la producción industrial simplemente por amenazas de accidentes. Los afectados por el riesgo deben quedar incluidos en el momento de definir el «riesgo aceptable». Debe tenerse en cuenta el hecho de que la expresión «riesgo aceptable» puede adoptar definiciones distintas en las diversas regiones europeas, incluso frente a amenazas comparables, ya que los aspectos socioculturales y la adaptabilidad a los peligros influyen en la percepción del riesgo. En la actualidad, las comunidades que investigan los peligros son insulares y rara vez interactúan con todos los sectores, las disciplinas, las regiones y las culturas individuales. En consecuencia, existen métodos diferentes para la evaluación de peligros y riesgos para los distintos tipos de peligros. De hecho, sería más adecuado tomar decisiones en una situación de múltiples riesgos, 
sobre todo cuando se trata de la dimensión territorial del riesgo. Por lo tanto, se necesita una perspectiva más homogénea e interdisciplinar para la evaluación y la gestión de los peligros y riesgos (por ejemplo, Schmidt-Thomé 2006, Greiving 2006b, IRGC 2005).

\section{La gestión pública de los riesgos}

Al abordar la gestión pública de los riesgos, hay que alcanzar un consenso sobre lo que significa «riesgo». Dejando de lado los problemas de interpretación, «riesgo» posee dos dimensiones distintas:

- La dimensión «fáctica», que comprende resultados que pueden medirse físicamente (por ejemplo, la combinación de consecuencias potenciales y la probabilidad de recurrencia de un suceso potencialmente dañino). Esta dimensión está representada por la evaluación de riesgos y puede entenderse principalmente como una labor analítica, gestionada por expertos de la administración pública respaldados, en muchos casos, por informes o declaraciones de expertos.

- La dimensión «sociocultural», que comprende cómo se percibe un riesgo concreto (por ejemplo, el que un riesgo se estime aceptable, tolerable o intolerable por la sociedad viene influido en parte por la forma en que se percibe que perturba el sistema de valores de la sociedad). Este componente sociocultural debe distinguirse del componente individual (cómo perciben y calculan el riesgo las diferentes personas) y del colectivo, influido por las situaciones culturales y, aún más, por los medios de difusión modernos (WBGU 1999). En este punto, resulta pertinente señalar que la atención persistente de los medios, al igual que la tecnología, a los fenómenos naturales destruye la confianza porque la mayor parte de lo que los medios presentan son noticias que destruyen la confianza.

Los dos hallazgos anteriores (que las comunidades de riesgo suelen ser insulares y que existen dos dimensiones de riesgo diferentes) suponen un desafío para cualquier planteamiento de gestión pública de los riesgos. En última instancia, este desafío requiere una forma integrada de tratar los riesgos con el objeto de crear comunidades resilientes. Las estrategias integradoras se dirigen hacia sinergias entre el asesoramiento científico, la participación/comunicación públicas y la gestión pública de los riesgos. Se precisan instrumentos que mejoren la solidez de la creación de políticas ante una alta incertidumbre y ambigüedad.

La incertidumbre y la ambigüedad son los principales retos a la hora de tratar los riesgos en la sociedad (Klinke \& Renn 2002).

- La incertidumbre reduce la confianza en una cadena estimada de causa-efecto. Es posible que esté relacionada con la incidencia, además de con la magnitud de un efecto peligroso. Para tratar la incertidumbre, la resiliencia constituye un objetivo adecuado para evitar irreversibilidades y vulnerabilidades.

- La ambigüedad indica la variabilidad de interpretaciones legítimas basadas en observaciones o evaluaciones de datos idénticas. La ambigüedad se produce por las diferencias entre los criterios o las normas para la interpretación o la estimación de una situación dada. Por consiguiente, debe buscarse una vía que cuente con amplia aceptación social para resolver los conflictos de valores y garantizar un trato justo de los intereses y puntos de vista mediante un discurso que procure el consenso. 
Con esta argumentación queda claro por qué la gestión de los riesgos está sometida a un proceso de politización cada vez mayor. A menudo, los riesgos medidos estadísticamente no coinciden con los riesgos percibidos. Algunos riesgos inminentes reciben menos atención que otros que son, desde el punto de vista estadístico, menos relevantes. Esta característica significa que cualquier proceso de gestión de riesgos debe estar familiarizado con la interpretación social del riesgo, es decir, con la forma en que lo perciben las distintas partes interesadas. Por lo tanto, los que gestionan y comunican los riesgos al público deben empezar por comprender las respuestas emocionales de los afectados.

Los principios de gestión pública de riesgos deben estar sujetos al compromiso de los responsables en los más altos niveles, además de una implantación práctica en todos los niveles. El desarrollo de un proceso de gestión pública implica consultar y lograr la participación de las partes interesadas en la evaluación y la gestión de los riesgos. La confianza en los procesos de toma de decisiones es fundamental para la interpretación de los riesgos por parte de los ciudadanos respecto a la percepción de peligros y riesgos «reales» y también para lograr una puesta en práctica de las decisiones que han de ser aceptabas para mitigar los riesgos. Las definiciones de riesgo afectan a las políticas, además de que definir el riesgo constituye una expresión de poder. En este sentido, Slovic argumenta que el que controla la definición de riesgo controla la política tecnológica (Slovic 1999). En consecuencia, la comprensión de «riesgo» da lugar a un concepto normativo que tiene un componente jurídico y legal (Greiving 2002). En la actualidad, la investigación y la práctica de la gestión pública de los riesgos está fragmentada según el tema y las organizaciones interesadas que disponen de presupuesto. Las últimas décadas demuestran (los ejemplos serían grandes inundaciones fluviales, tormentas de invierno e incendios forestales) que el riesgo para nuestro tejido social traspasa los límites entre Estados-nación, empresas, gobiernos y comunidades ricas y pobres. La compleja interdependencia del riesgo exige un planteamiento sistemático de la gestión pública a fin de garantizar la resiliencia y la sostenibilidad de nuestro tejido económico en Europa y en el resto del mundo. Hasta ahora, apenas se empleaba la gestión pública de los riesgos para formular estrategias de gestión de desastres naturales y la resiliencia a los riesgos está integrada de forma deficiente en las estrategias que tratan los peligros naturales. Esta carencia se ha hecho más evidente en la pobre actuación de las agencias encargadas de la respuesta de emergencia durante el periodo posterior al huracán Katrina.

El objetivo material de «resiliencia» (otra expresión similar empleada, por ejemplo en la investigación sobre el cambio climático, es «capacidad de adaptación») puede interpretarse como una estrategia ampliamente aceptada dentro de la comunidad encargada de tratar los desastres naturales. Frente a esto, se ha elaborado un planteamiento más procedimental para la «gestión pública de riesgos», que se ha adoptado, en primer lugar, en el ámbito de los riesgos emergentes, principalmente creados por el hombre. Debe interpretarse el uso de las dos expresiones en el mismo contexto como una estrategia innovadora para compaginar un camino adecuado (gestión pública de riesgos, que incluye la identificación, la evaluación y la comunicación del riesgo) hacia el objetivo material de crear comunidades resilientes capaces de afrontar una amplia gama de riesgos, ya sean naturales o creados por el hombre.

Estos elementos tan potentes, que tienen en cuenta a las partes interesadas, han quedado integrados en las estrategias de gestión de desastres (ISR 2005). Además, se han identificado a los inadaptados en la interrelación entre las instituciones y las partes interesadas como motivos considerables para la vulnerabilidad institucional (Greiving 2005). 


\section{El papel de la ordenación territorial}

No existe una responsabilidad integral de la gestión de los riesgos derivados de los peligros naturales en Europa, ni en sus Estados miembro. Por lo general, las autoridades que están a cargo de la evaluación y la gestión de los riesgos son diferentes, una para cada tipo de peligro. No obstante, la gestión de los riesgos pertenece también a las 13 funciones de la ordenación territorial. Efectivamente, la ordenación territorial desempeña un papel destacado en la mitigación, cuyo objetivo es la reducción del daño a la población, los bienes y los recursos tomando medidas antes de que se produzca el desastre (por ejemplo, Schmidt-Thomé 2006).

La expresión «ordenación territorial» se utiliza en varios Estados miembros (y, por supuesto, su traducción al inglés): algunos emplean «planificación de la explotación del suelo» (por ejemplo, Irlanda), «ordenación territorial» (Italia), «ordenación del espacio» (Alemania - Raumplanung), otros emplean «desarrollo territorial» (Polonia - Zagospodarowanie przestrzenne), «ordenación del desarrollo regional» (Francia - aménagement du territoire). Así, la utilización y la comprensión de «ordenación territorial» están muy abiertas. Por este motivo resulta importante disponer de definiciones claras que eviten errores. Vamos a examinar las definiciones respecto a la ordenación territorial. La siguiente tabla ofrece una visión general de varias formas de ordenación:

Tabla 2

VISIÓN GENERAL DEL SISTEMA DE ORDENACIÓN EUROPEO

\begin{tabular}{|c|c|c|c|}
\hline Ámbito espacial & $\begin{array}{l}\text { Planificación con } \\
\text { carácter espacial }\end{array}$ & & $\begin{array}{l}\text { Planificación sin ca- } \\
\text { rácter espacial }\end{array}$ \\
\hline & Integral & $\begin{array}{l}\text { Sectorial (transporte, } \\
\text { agua, geología, emergen- } \\
\text { cias, etc.) }\end{array}$ & $\begin{array}{l}\text { Planificación sin ca- } \\
\text { rácter espacial a dis- } \\
\text { tintas escalas }\end{array}$ \\
\hline Europa & $\begin{array}{l}\text { Ordenación terri- } \\
\text { torial europea (no } \\
\text { vinculante) }\end{array}$ & $\begin{array}{l}\text { Política medioambiental, } \\
\text { TEN, CAP }\end{array}$ & $\begin{array}{l}\text { P. ej. Planificación de } \\
\text { presupuestos }\end{array}$ \\
\hline Estados miembros & $\begin{array}{l}\text { Ordenación terri- } \\
\text { torial }\end{array}$ & $\begin{array}{l}\text { Ej. Red Nacional de } \\
\text { transporte }\end{array}$ & $\begin{array}{l}\text { P. ej. Planificación en } \\
\text { defensa, educación, } \\
\text { etc. }\end{array}$ \\
\hline $\begin{array}{l}\text { Nivel inferior al esta- } \\
\text { tal (Estados federales, } \\
\text { regiones, u otras uni- } \\
\text { dades espaciales) }\end{array}$ & $\begin{array}{l}\text { Planificación pro- } \\
\text { vincial (en parte } \\
\text { relacionada con la } \\
\text { planificación del } \\
\text { uso del suelo) }\end{array}$ & $\begin{array}{l}\text { por ej.: autoridades de } \\
\text { cuencas fluviales encar- } \\
\text { gadas de la gestión de } \\
\text { planes, en parte relacio- } \\
\text { nada con la ordenación y } \\
\text { gestión territorial }\end{array}$ & $\begin{array}{l}\text { por ej.: desarrollo cul- } \\
\text { tural, planificación } \\
\text { educativa }\end{array}$ \\
\hline $\begin{array}{l}\text { Municipio (toda la or- } \\
\text { denación en este nivel } \\
\text { puede aglutinarse con } \\
\text { la expresión «pla- } \\
\text { nificación y gestión } \\
\text { urbanística») }\end{array}$ & $\begin{array}{l}\text { Planificación local } \\
\text { del uso del suelo }\end{array}$ & $\begin{array}{l}\text { por ej.: planificación } \\
\text { de aguas residuales, del } \\
\text { transporte público, los } \\
\text { municipios se encargan } \\
\text { de la planificación de la } \\
\text { explotación del suelo. }\end{array}$ & $\begin{array}{l}\text { por ej.: educación pri- } \\
\text { maria, planificación } \\
\text { del presupuesto mu- } \\
\text { nicipal }\end{array}$ \\
\hline
\end{tabular}

Fuente: Greiving (2006). 
Por su naturaleza, la tarea de evaluación de los peligros corresponde a las autoridades sectoriales, como las juntas de agua y las inspecciones geológicas. A pesar de que la ordenación territorial desempeña un papel menor, es un usuario final importante de la información relacionada con los peligros suministrada por las autoridades sectoriales. Para cumplir los requisitos de la ordenación territorial, son indispensables unos niveles mínimos para la cartografía de los peligros. Sin embargo, apenas se presta atención a la vulnerabilidad.

Desde el punto de vista de la ordenación territorial, es necesaria toda esa información que no se encuentra disponible, o cuando menos no la pueden determinar los propios encargados de la ordenación, lo cual significa que, en primera instancia, las autoridades sectoriales deben facilitar la información relacionada con los peligros. Este tipo de información incluye la intensidad y la magnitud de sucesos potencialmente dañinos. Por otro lado, en la mayoría de los casos, los responsables de la ordenación territorial disponen de la información relacionada con la vulnerabilidad porque los datos como la distribución de la población, la situación de las zonas de asentamiento o infraestructuras técnicas son fundamentales para cualquier tipo de actividad de planificación (véase Fleischhauer et al. 2006).

La gestión de los riesgos se define como políticas de ajuste que reducen las posibilidades de pérdidas causadas por sucesos extremos. Esta definición pone de manifiesto que la gestión de los riesgos está influida por las decisiones de las partes interesadas. La toma de decisiones constituye una estrategia normativa, influida por la política, respecto a tolerar o cambiar los riesgos. La autoridad encargada debe decidir los objetivos principales de la ordenación para tratar los peligros. El resultado se logra al ponderar los diversos aspectos. Las siguientes preguntas son pertinentes en este caso:

- ¿Cuál es el nivel de riesgo que una sociedad (o cualquier parte interesada) está dispuesta a aceptar?

- ¿Cuáles son los objetivos de protección de los distintos objetos de protección que están amenazados por peligros específicos? O, ¿cuáles son los efectos medioambientales previstos para un objeto planeado en caso de que se produzca un peligro?

La ordenación territorial es sólo uno de los muchos elementos del ciclo completo de desastres, que se compone de la mitigación, la preparación, la respuesta y la recuperación. Además, la evaluación del riesgo específico corresponde a los actores especializados en cada país que figuran en la tabla 3:

Se considera que los actores que figuran en la tabla 3 (anteriormente) son actores clave en el ámbito de la mitigación dirigida a reducir los daños a las personas, a los bienes y a los recursos mediante medidas tomadas antes de que se produzca un desastre natural. El objetivo es reducir la vulnerabilidad y la exposición a los desastres. La mitigación de los peligros se refiere a acciones que tienen efectos a largo plazo (por ejemplo, ordenación territorial como actividades de mitigación no estructurales, pero también la mitigación estructural, como reforzar las infraestructuras de protección o los edificios mediante, por ejemplo, el cambio de ubicación de los sistemas de calefacción o las instalaciones eléctricas de los sótanos a pisos superiores).

Al tratar la gestión de los riesgos, es necesario distinguir entre el ámbito regional y el local, por lo que debe indicarse claramente qué objetivos, instrumentos, etc. pueden aplicarse en cada ámbito.

La tabla 4 distingue la planificación regional, la planificación de la explotación del suelo y las autoridades sectoriales. También se mencionan los instrumentos de apoyo. Más adelante, analizaremos exhaustivamente el papel de la planificación regional, así como el de la planificación de la explotación del suelo. 
Tabla 3

MEDIDAS DE REDUCCIÓN DEL RIESGO, ACTORES Y POLÍTICAS EN DIFERENTES PAIISES EUROPEOS

\begin{tabular}{|c|c|c|c|c|c|c|c|c|}
\hline PAÍS & $\begin{array}{c}\text { Peligros } \\
\text { contemplados en } \\
\text { la planificación } \\
\text { territorial }\end{array}$ & $\begin{array}{c}\text { Autoridad } \\
\text { encargada } \\
\text { de la } \\
\text { planificación } \\
\text { de riesgos }\end{array}$ & $\begin{array}{c}\text { Existencia de } \\
\text { cartografía } \\
\text { de } \\
\text { peligrosidad }\end{array}$ & $\begin{array}{l}\text { Existencia } \\
\quad \text { de } \\
\text { cartografía } \\
\text { de riesgos }\end{array}$ & $\begin{array}{l}\text { Empleo de } \\
\text { indicadores de } \\
\text { vulnerabilidad }\end{array}$ & $\begin{array}{l}\text { Gestión } \\
\text { de riesgos } \\
\text { múltiples }\end{array}$ & $\begin{array}{c}\text { Autoridad } \\
\text { encargada } \\
\text { de la } \\
\text { gestión de } \\
\text { riesgos }\end{array}$ & $\begin{array}{l}\text { Importancia } \\
\text { de la } \\
\text { concienciación } \\
\text { ciudadana }\end{array}$ \\
\hline Finlandia & $\begin{array}{c}\text { FL, LS, } \\
\text { FF, EQ, } \\
\text { EE }\end{array}$ & SA & o & - & PD & - & SA, SP & o \\
\hline Francia & $\begin{array}{l}\text { LS, FL, } \\
\text { FF, EQ }\end{array}$ & SA & + & o & PD & + & SA, SP & + \\
\hline Alemania & $\begin{array}{l}\text { FL, LS, } \\
\text { EE, LS }\end{array}$ & SA & + & o & DP & - & SA, SP & 0 \\
\hline Grecia & $\begin{array}{l}\text { FL, FF, } \\
\text { VO, EQ }\end{array}$ & SA & o & o & Sin datos & - & SA, SP & o \\
\hline Italia & $\begin{array}{l}\text { FL, LS, } \\
\text { VO, FF }\end{array}$ & SA & o & 0 & Sin datos & 0 & SA, SP & Sin datos \\
\hline Polonia & $\begin{array}{l}\text { LS, FL, } \\
\text { FF, EQ }\end{array}$ & SA & 0 & 0 & $\begin{array}{l}\text { DP, PD, } \\
\text { OI }\end{array}$ & - & SA, SP & + \\
\hline España & $\begin{array}{c}\text { FL, LS, } \\
\text { FF, VO, } \\
\text { EQ }\end{array}$ & SA & + & 0 & $\mathrm{PD}, \mathrm{OI}$ & - & SA, SP & Sin datos \\
\hline $\begin{array}{l}\text { Reino } \\
\text { Unido }\end{array}$ & LS, FL & SA & 0 & 0 & Sin datos & - & SA, SP & + \\
\hline
\end{tabular}

$\mathrm{LS}=$ desprendimientos de tierras

$\mathrm{FL}=$ inundaciones

$\mathrm{FF}=$ incendios forestales

$\mathrm{VO}=$ peligros volcánicos

$\mathrm{EQ}=$ terremotos

$\mathrm{EE}=$ sucesos meteorológicos extremos

$\mathrm{CC}=$ cambio climático

$\mathrm{LS}=$ desprendimientos de tierras

$\mathrm{FL}=$ inundaciones
$\mathrm{SA}=$ autoridad sectorial

$\mathrm{SP}=$ ordenación territorial

$\mathrm{DP}=$ daños económicos en potencia

$\mathrm{PD}=$ densidad de población

$\mathrm{OI}=$ otros indicadores

$+=$ alta importancia/sí

$\mathrm{o}=$ importancia media/en parte

- = baja importancia o sin importancia/no

Fuente: Fleischhauer et al. (2006). 
Tabla 4

CONTRIBUCIÓN DE LA PLANIFICACIÓN RELATIVA AL TERRITORIO E INSTRUMENTOS DE APOYO A LAS ESTRATEGIAS DE GESTIÓN DE RIESGOS

\begin{tabular}{|c|c|c|c|c|}
\hline $\begin{array}{l}\text { Estrategia } \\
\text { de gestión de } \\
\text { riesgos }\end{array}$ & $\begin{array}{l}\text { A. Planificación } \\
\text { regional }\end{array}$ & $\begin{array}{c}\text { B. Planificación } \\
\text { de explotación } \\
\text { del suelo }\end{array}$ & $\begin{array}{l}\text { C. Autoridades } \\
\text { sectoriales }\end{array}$ & $\begin{array}{l}\text { D. Instrumentos } \\
\text { de apoyo }\end{array}$ \\
\hline $\begin{array}{l}\text { 1. Mitigación } \\
\text { dirigida a la } \\
\text { prevención }\end{array}$ & $\begin{array}{l}\text { P.ej.: ordenación, } \\
\text { asentamientos y es- } \\
\text { tructuras de trans- } \\
\text { porte que causan } \\
\text { menos emisiones } \\
\text { de gases de efecto } \\
\text { invernadero }\end{array}$ & $\begin{array}{l}\text { Respaldo a la uti- } \\
\text { lización de ener- } \\
\text { gías renovables }\end{array}$ & $\begin{array}{l}\text { Estrategias para } \\
\text { reducir las emi- } \\
\text { siones de gases } \\
\text { de efecto inver- } \\
\text { nadero (p. ej. } \\
\text { estructuras de } \\
\text { transportes) }\end{array}$ & $\begin{array}{l}\text { Protocolo de } \\
\text { Kioto; estrategias } \\
\text { para la reducción } \\
\text { de las emisiones } \\
\text { de gases de efec- } \\
\text { to invernadero, } \\
\text { sistema fiscal }\end{array}$ \\
\hline $\begin{array}{l}\text { 2. Mitigación } \\
\text { no estructu- } \\
\text { ral (a): re- } \\
\text { ducción de } \\
\text { los impactos } \\
\text { de los peli- } \\
\text { gros }\end{array}$ & $\begin{array}{l}\text { Mantenimiento de } \\
\text { las características } \\
\text { de protección del } \\
\text { medio natural que } \\
\text { absorben o reducen } \\
\text { los impactos de los } \\
\text { peligros (zonas de } \\
\text { retención, dunas de } \\
\text { arena) }\end{array}$ & $\begin{array}{l}\text { Filtración local } \\
\text { de las aguas } \\
\text { pluviales }\end{array}$ & $\begin{array}{l}\text { Planes de protec- } \\
\text { ción de inunda- } \\
\text { ciones, planes de } \\
\text { protección coste- } \\
\text { ra, reforestación, } \\
\text { cultivos de la tie- } \\
\text { rra adaptados }\end{array}$ & \multirow[t]{3}{*}{$\begin{array}{l}\text { Cooperación inte- } \\
\text { rregional, instru- } \\
\text { mentos económi- } \\
\text { cos, gestión de la } \\
\text { información }\end{array}$} \\
\hline $\begin{array}{l}\text { 3. Mitigación } \\
\text { no estructu- } \\
\text { ral (b): re- } \\
\text { ducción de } \\
\text { los daños po- } \\
\text { tenciales }\end{array}$ & $\begin{array}{l}\text { Calificaciones en } \\
\text { planes regionales } \\
\text { como zonas de } \\
\text { riesgo de inunda- } \\
\text { ciones }\end{array}$ & $\begin{array}{l}\text { Instrumentos de } \\
\text { zonificación }\end{array}$ & $\begin{array}{l}\text { Adecuada asig- } \\
\text { nación de recur- } \\
\text { sos de amenaza } \\
\text { de la infraestruc- } \\
\text { tura }\end{array}$ & \\
\hline $\begin{array}{l}\text { 4. Mitigación } \\
\text { estructural }\end{array}$ & $\begin{array}{l}\text { Garantizar la via- } \\
\text { bilidad del espacio } \\
\text { para las infraes- } \\
\text { tructuras de pro- } \\
\text { tección }\end{array}$ & $\begin{array}{l}\text { Medidas de pre- } \\
\text { vención como } \\
\text { parte de las li- } \\
\text { cencias de cons- } \\
\text { trucción }\end{array}$ & $\begin{array}{l}\text { Proyectos de in- } \\
\text { geniería, infra- } \\
\text { estructuras de } \\
\text { protección (di- } \\
\text { ques en líneas de } \\
\text { costas) }\end{array}$ & \\
\hline $\begin{array}{l}\text { 5. Reacción: } \\
\text { preparación, } \\
\text { respuesta, re- } \\
\text { cuperación }\end{array}$ & & $\begin{array}{l}\text { Re-ordenadar el } \\
\text { territorio }\end{array}$ & $\begin{array}{l}\text { Planes de emer- } \\
\text { gencia, ej. Infor- } \\
\text { me SEVESO II }\end{array}$ & $\begin{array}{l}\text { Información e } \\
\text { educación para } \\
\text { mejorar la con- } \\
\text { cienciación y la } \\
\text { gestión de emer- } \\
\text { gencias }\end{array}$ \\
\hline
\end{tabular}

Fuente: Greiving/Fleischhauer 2006.

El papel de la ordenación territorial en la mitigación incluye las siguientes acciones, que deben tomarse en distintos ámbitos de ordenación (provincial, local):

- Ordenación regional: Proporciona un marco relativamente general para los planes y los programas locales y sectoriales (incluso en Alemania y otros países en los que 
existen instrumentos normativos de ordenación en el ámbito regional). Así, basta con identificar las zonas con amenazas potenciales a fin de evitar, por ejemplo, más actividades de asentamiento.

- Planificación de la explotación del suelo: En el ámbito local, se necesita una evaluación de los peligros más detallada. Debe entenderse la planificación de la explotación del suelo en la mayoría de los países como un fundamento vinculante para las licencias de construcción, basado en calificaciones concretas relativas a terrenos concretos. Para adoptar calificaciones restrictivas y protectoras del uso del suelo por peligros en potencia por un lado y por la vulnerabilidad de los posibles usos del suelo y de la construcción por otro lado, resulta crucial disponer de información precisa sobre los peligros, incluso para los planos preparatorios de la explotación del suelo.

Las siguientes estrategias deben contemplarse como los elementos principales de la respuesta a los desastres en la ordenación territorial:

- Mantener las zonas libres de explotación: La ordenación territorial dispone de los siguientes criterios para mantener zonas del territorio libres de explotaciones futuras:

(a) propensas a peligros (por ejemplo, zonas propensas a inundaciones, zonas propensas a avalanchas)

(b) necesidad de reducir los efectos de un suceso peligroso (por ejemplo, zonas de retención de agua)

(c) necesidad de garantizar la eficacia de las actividades de respuesta (por ejemplo, vías de escape y puntos de reunión).

- Decisiones diferenciadas sobre el uso del suelo: Aparte de mantener determinadas zonas libres de explotación, la ordenación territorial también puede decidir sobre los tipos aceptables de uso del suelo según la intensidad y la frecuencia del peligro existente (por ejemplo, podría permitirse el uso agrícola de una zona propensa a inundaciones mientras que se prohibiría el uso residencial).

- Recomendaciones en los planes jurídicamente vinculantes sobre el uso o la calificación del suelo: Aunque las recomendaciones sobre determinados requisitos de construcción pertenecen al ámbito de las licencias de construcción, se pueden emitir recomendaciones en cuanto al uso o la calificación del suelo (por ejemplo, altura mínima de elevación de los edificios, prohibición de sótanos, prohibición de calefacción por fuel y tipo de tejado).

- Influencia de la ordenación territorial en la intensidad y frecuencia de los peligros (= potencial de peligro): La ordenación territorial también puede contribuir a reducir el potencial de peligro, por ejemplo protección o alcance de las zonas de retención de inundaciones fluviales, bosques protectores, etc.

Para cumplir su función en la mitigación de desastres, la ordenación territorial precisa de información adecuada y fiable en la que basar las decisiones sobre qué zonas deben mantenerse libres, qué usos del suelo pueden permitirse, qué restricciones deben prescribirse para la edificación y dónde la ordenación puede contribuir a la mitigación de peligros. Para cada una de esas decisiones, para cada ámbito de la ordenación y para cada peligro, la ordenación territorial cuenta con determinados requisitos sobre la información sobre los peligros.

En este aspecto, la práctica actual se halla muy lejos de los avances tecnológicos, según se describe a continuación (véase Fleischhauer et al 2006). Desde el punto de vista de la 
ordenación territorial, la cuestión central consiste en estudiar cuánta información sectorial (sobre todo el alcance y la intensidad de los peligros) se traslada a los distintos ámbitos territoriales en términos del territorio. Se puede mostrar la intensidad de un peligro diferenciando las zonas propensas a desastres según la intensidad del peligro.

Un mapa de peligros múltiples constituye, en primera instancia, la suma de todos los mapas de los peligros individuales. Además, hay que tener en cuenta las posibles interacciones y los efectos acumulativos. En una zona específica, se establecerán restricciones según el mayor peligro existente en dicha zona (independientemente de cuál sea el peligro).

Debe señalarse claramente que la información relacionada con el peligro suministrada por las autoridades sectoriales debe ser traducida al lenguaje de la ordenación territorial. El carácter vinculante de la calificación del suelo pasa a formar parte del carácter vinculante de todo el plan territorial, lo cual significa que la ordenación territorial debe tener en cuenta la información suministrada sobre peligros y, como parte del proceso de toma de decisiones, adoptar las decisiones según el tipo de explotación y la intensidad del peligro en la zona en que va a producirse la explotación.

Los distintos tipos de riesgo requieren respuestas adecuadas que presten atención a la resistencia, la resiliencia y la retirada según el nivel del peligro y su aceptabilidad. En este punto, se necesita una base científica fáctica para tomar decisiones normativas. Ha de tener en cuenta las distintas características de los riesgos de los peligros naturales. Las curvas de riesgo de la siguiente figura presentan un pico en el punto en el que el daño medio anualizado está en el máximo. Un riesgo máximo puede ser el resultado de un daño medio moderado en combinación con una alta frecuencia o, igualmente, el resultado de un daño alto con una frecuencia baja. Según el riesgo máximo identificado, pueden definirse los tipos de riesgos para encontrar las medidas de gestión de los riesgos (Greiving 2006a).

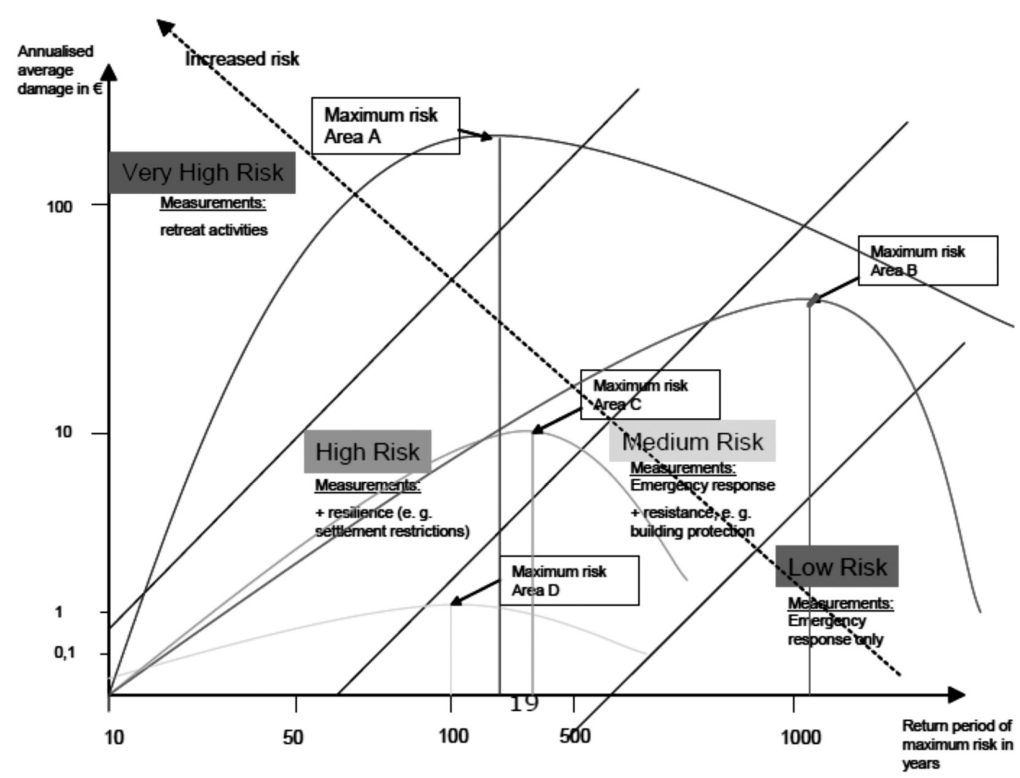

FIgURA 1. De la evaluación de los riesgos a la gestión de los riesgos. Fuente: Greiving 2006a. 
Esta metodología es factible, fácilmente comprensible y, por tanto, puede servir como base para tomar decisiones aceptables. Resulta razonable que un riesgo máximo más elevado justifique medidas de mitigación más drásticas, como la reubicación de los asentamientos existentes, que las de un riesgo más bajo. Al final, se pueden tolerar algunos usos del suelo menos vulnerables (actividades al aire libre temporales, usos agrícolas intensivos) incluso en las zonas de riesgo. Cualquier propuesta de transformación de los usos del suelo requiere una nueva evaluación de los riesgos que muestre cómo la transformación propuesta modificará:

- los niveles existentes de peligros

- los niveles existentes de exposición

- los niveles existentes de vulnerabilidad física

- los niveles existentes de capacidad de reajuste

En otras zonas, un nivel inferior de riesgo puede requerir medidas menos graves (resiliencia y/o resistencia).

No obstante, la posible influencia del cambio climático puede incidir sobre un riesgo concreto, con lo que se necesitaría una respuesta nueva. La repercusión del cambio climático en el riesgo y, por ende, en la racionalidad de determinadas medidas de gestión también puede expresarse en términos de su eficacia cambiante, según se ilustra en la figura 2 a continuación.

En la actualidad, puede ser aún más eficaz continuar como antes sin tomar medidas. En caso de que se produzca un suceso, la sociedad simplemente resiste los daños («resistencia»). Con el tiempo y, por ejemplo, con un nivel del mar en aumento, resulta eficaz proteger las zonas con determinadas medidas, según se muestra en la figura 1. En el punto de inflexión, la proporción entre costes marginales y beneficios marginales se reduce y la eficacia disminuye («resiliencia»). Por último, las medidas de protección adicionales dejan de ser eficaces («retirada»). Las hipótesis de evolución pueden justificar los cambios en

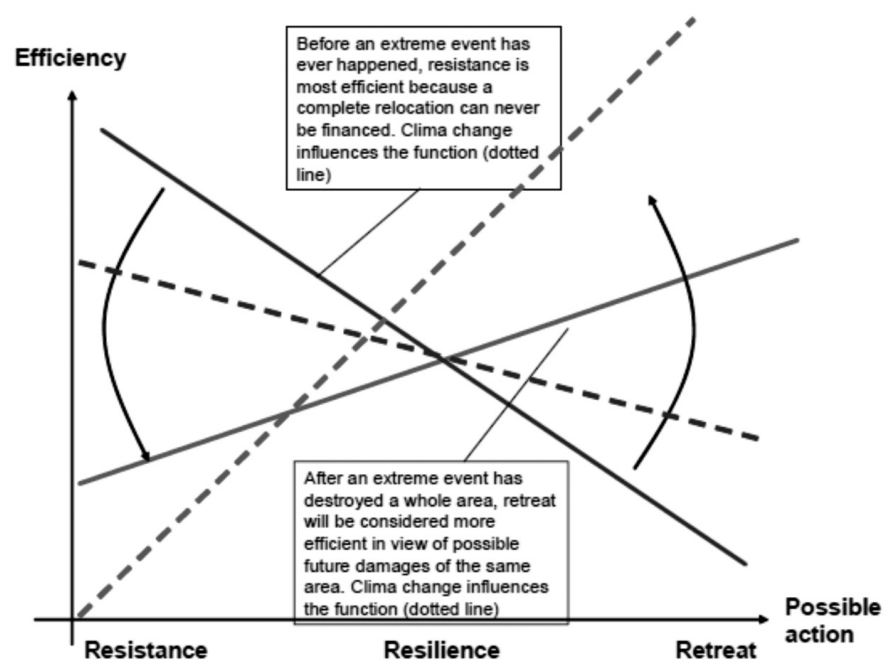

Figura 2. Cambio en la eficacia de las acciones/medidas según la incidencia de los desastres. 
las «curvas de eficacia». El cambio climático influirá la función, por lo que el punto de inflexión se desplaza hacia la izquierda: resiliencia, y la retirada resulta más eficaz, incluso antes de que tenga lugar el desastre natural.

Cabe preguntarse cuáles son las implicaciones de lo anterior para la ordenación territorial frente a la práctica actual.

- Fase de resistencia: «Plan A» (riesgo bajo, significa que no se requiere ningún plan que considere los peligros y la vulnerabilidad excepto la respuesta de emergencia).

- Fase de resiliencia: Riesgo medio a alto. Mejora del Plan A con el objeto de tener en cuenta los peligros y la vulnerabilidad debido a las repercusiones del cambio climático: mejora de la protección (para zonas altamente vulnerables según el riesgo concreto, véase la figura 1). Sin embargo, al mismo tiempo, la ordenación debería empezar a plantearse nuevas estructuras territoriales para cuando las medidas de protección adicionales dejen de ser eficaces («Plan B»): reubicación (usos del suelo altamente vulnerables) y adaptación de la protección (por ejemplo, mejora de las estructuras para aquellos usos del suelo que siguen siendo beneficiosos en las zonas amenazadas). De este modo, la sociedad estará mejor preparada para recuperarse tras un desastre, que puede tomarse como una oportunidad. Un asentamiento totalmente nuevo estaría listo para su puesta en práctica y reconstruir las instalaciones destruidas de forma diferente.

- Fase de retirada: Riesgo muy alto debido a las constantes repercusiones del cambio climático. Abandonar completamente la zona tras las medidas adicionales (resiliencia) ya no es eficaz («Plan C»).

En la siguiente figura se muestran las distintas fases y los diversos grados de conveniencia de las medidas de resiliencia mediante el ejemplo de las zonas costeras afectadas por la subida del nivel del mar:

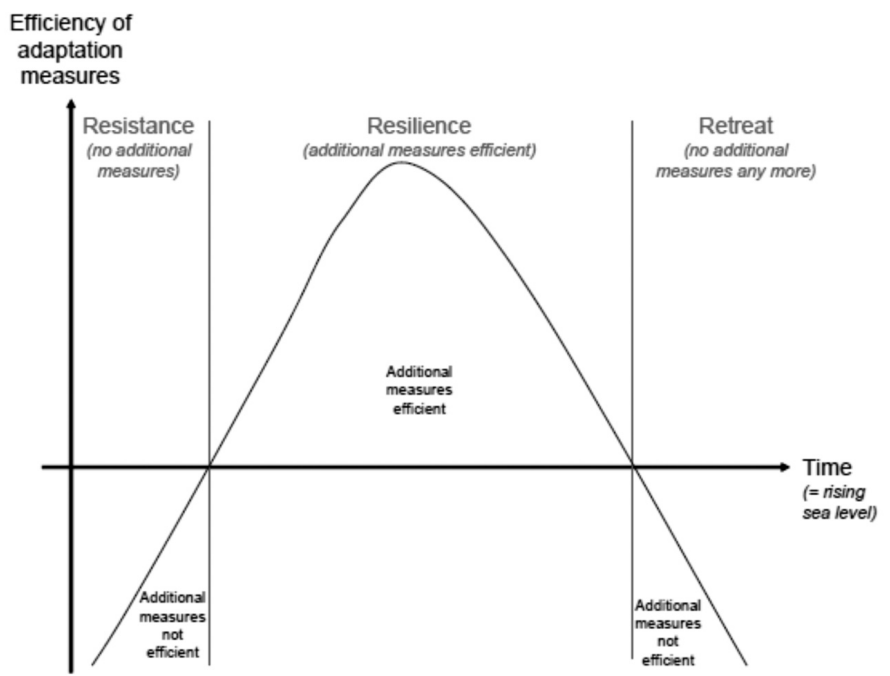

Figura 3. Cambio en la eficacia de las medidas de adaptación con el tiempo (por ejemplo, a causa de la subida del nivel del mar. 


\section{Aplicaciones prácticas de las estrategias analizadas aplicación de los resultados del proyecto ESPON sobre peligros a las estrategias y políticas de la UE}

En la primera parte del presente estudio hemos esbozado la distribución de los peligros naturales en el territorio europeo, junto con los posibles efectos del cambio climático en dichos peligros. A continuación, hemos destacado la importancia de la gestión y la gestión pública de los riesgos en la categorización y la comprensión de esos riesgos para la sociedad. Hemos definido la ordenación territorial como el instrumento que probablemente encierra el mayor potencial para gestionar los peligros y los riesgos en el desarrollo territorial. Pero, ¿hacia dónde podemos llevar lo anterior desde el punto de vista de Europa? Ahora vamos a analizar una serie de ejemplos de aplicaciones del proyecto ESPON sobre Peligros. Se trata sólo de los primeros pasos, pero se pueden integrar en una estrategia europea para gestionar mejor los riesgos medioambientales, lo que redundará en un desarrollo territorial sostenible.

Se han utilizado los resultados del proyecto ESPON sobre peligros para exponer los temas relacionados de riesgos y peligros analizados en la Agenda territorial de la Unión Europea (2007) y en su documento de referencia, El estado y las perspectivas territoriales de la Unión Europea (2007). El objetivo de la Agenda Territorial es establecer un marco relativo a la acción y a la estrategia encaminado a respaldar el desarrollo territorial. Uno de los objetivos trazados para la estrategia de la Unión Europea consiste en la cohesión territorial (junto a la cohesión económica y social), dado que muchos de los problemas estructurales de la UE tienen sus raíces en las disparidades económicas territoriales. Así, la Agenda Territorial apoya los objetivos de las estrategias de Lisboa (competitividad europea) y Gotemburgo (desarrollo sostenible). La Comisión Europea ha resaltado la importancia de los riesgos medioambientales y del cambio climático para el desarrollo regional (Comisión Europea 2006).

La Agenda Territorial incluye información sobre estas cuestiones. Este desarrollo llegó con bastante rapidez, ya que no se percibía que los peligros naturales y el cambio climático fueran pertinentes para el desarrollo regional en los borradores de los proyectos de desarrollo regional europeo del Programa INTERREG III (2000-2007). Las propuestas de proyectos que abordaban esos asuntos se toparon con dificultades debido a que se las solía tachar de «fuera del ámbito de aplicación». Gracias al citado aumento de los costes causados por los desastres y a la mayor cobertura de esas cuestiones por los medios de comunicación (Schmidt-Thomé 2006), se produjo un cambio en la percepción. De este modo, los principales hallazgos del proyecto ESPON sobre Peligros (es decir, una visión general sobre la distribución geográfica de los peligros naturales y los efectos previstos del cambio climático en dichos peligros) quedaron incluidos en la Agenda Territorial. Al contar con el respaldo de los ministros europeos responsables del desarrollo territorial, la Agenda tiene el poder de influir en las futuras estrategias de desarrollo territorial (y la financiación correspondiente) en la Unión Europea y en sus Estados miembro.

Asimismo, se han utilizado también los resultados del Proyecto ESPON sobre Peligros en un estudio para la Comisión Europea que analizaba los patrones de los peligros en Europa y los proyectos relativos a dichos peligros emprendidos con los Fondos Europeos de Desarrollo Regional (iniciativa INTERREG). En lo sucesivo se le denominará estudio ESPON-INTERACT sobre Peligros (Schmidt-Thomé et al. 2006 (2)). Después de que la Comisión Europea calificara a los riesgos medioambientales y el cambio climático de desafíos pertinentes para el desarrollo regional (Comisión Europea 2006), necesitaba información no sólo sobre las zonas afectadas, sino también sobre el estado actual de los conocimientos sobre los peligros desde una perspectiva regional. El estudio ESPON 


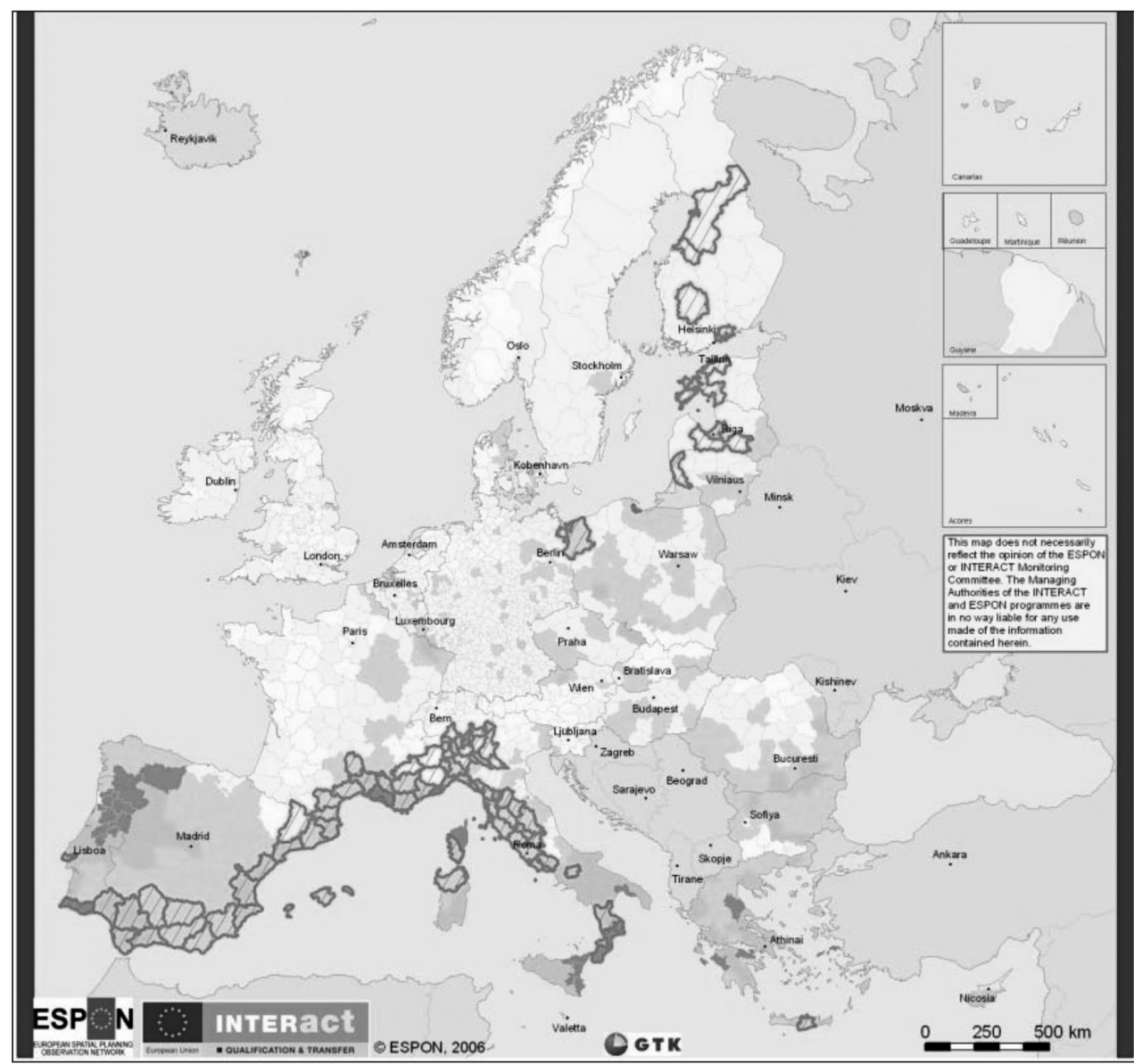

MAPA 2: Peligro de incendio forestal y proyectos de INTERREG IIIB relativos a los incendios forestales en las regiones europeas.

Fuente: Schmidt-Thomé et al. 2006 (2).

INTERACT sobre Peligros elaboró una base de datos que clasificaba los proyectos según los peligros estudiados y a qué capítulos de INTERREG estaban asignados. Quedó claro que el proyecto preliminar de ESPON sobre Peligros sólo podía ayudar a determinar las zonas con patrones evidentes de peligros que no habían sido estudiados hasta entonces en los proyectos de desarrollo regional. El estudio concluyó que, por ejemplo, las inundaciones, las sequías y las temperaturas extremas habían quedado cubiertas de forma exhaustiva en los proyectos de desarrollo regional, pero no tanto los incendios forestales $y$, lo que resultaba interesante, no estaban cubiertos en absoluto en algunas de las zonas más propensas a sufrirlos alrededor del Mediterráneo (Schmidt-Thomé y Schmidt-Thomé 2006), véase el Mapa 2 a continuación. Los resultados de ese estudio aplicado no buscaban criticar a ninguna región por su uso actual de los Fondos Europeos de Desarrollo Regional, sino dar indicaciones de dónde podían aplicarse dichos fondos en el futuro. 
Otro resultado relevante fue la visión panorámica empleada para crear un manual sobre evaluación y gestión de riesgos (Schmidt-Thomé 2005), analizado anteriormente. Se trataba de la respuesta a una petición de la Comisión y es posible que se amplíe más adelante.

\section{Ejemplos locales del apoyo a la ordenación ante el cambio climático}

Las complejas repercusiones de la subida del nivel del mar y del cambio de las zonas propensas a sufrir inundaciones en la región del mar Báltico dieron lugar a dos proyectos que se centraban en la comunicación entre las partes interesadas. Se creó un Marco de Apoyo para las Decisiones (Schmidt-Thomé y Peltonen 2006), que contiene directrices para la comunicación entre las distintas partes interesadas y proporciona información y casos prácticos que muestran las interacciones entre el cambio climático global y la ordenación local que ponen de manifiesto la necesidad última de emprender estrategias de mitigación.

El Marco está estructurado en una matriz de cuatro pilares que representan las labores y los instrumentos principales necesarios para comunicar la creación y el análisis de la hipótesis del nivel del mar de forma interdisciplinar, en colaboración con planificadores del espacio, además de autoridades locales y regionales y otras partes interesadas. El factor clave para tratar el sistema socioeconómico de una zona y mitigar los efectos negativos del cambio climático viene determinado por la evaluación de la vulnerabilidad. La base de conocimientos incluye los antecedentes existentes sobre aspectos jurídicos y de ordenación. Además, proporciona panorámicas breves y precisas respecto al estado actual de los estudios sobre el cambio climático y sirve de plataforma para hallar ejemplos en otros ámbitos de estudio y las mejores prácticas de las estrategias de mitigación del impacto del cambio climático. El cuarto pilar, la plataforma de debate, es el instrumento que respalda la colaboración al proporcionar ejemplos y métodos de las funciones y de los intereses de los actores y las redes implicadas.

El Marco de Apoyo para las Decisiones constituye una herramienta de estructuración y apoyo en la gestión de los riesgos. Es útil para determinados requisitos como la integración de aspectos científicos, económicos, sociales y culturales y para lograr la participación efectiva de las partes interesadas. Presenta una «interfaz de usuario» entre la investigación y la práctica que ofrece información de fácil acceso a los planificadores y a los responsables de las decisiones en distintos ámbitos territoriales, así como a otras partes interesadas. La gran ventaja del Marco es su transparencia y flexibilidad. El input del Marco no está restringido por ningún conjunto de datos normativo con requisitos mínimos, por lo que puede realizarse tan sólo con unos cuantos datos disponibles. De este modo, se puede iniciar el Marco con la base de un dictamen de expertos y puede mejorarse el conjunto de los datos de input cuando se disponga de más datos.

Se aplicó con éxito el Marco de Apoyo para las Decisiones en los casos prácticos del proyecto sobre los efectos del cambio del nivel del mar en la región del mar Báltico (SEAREG), por ejemplo en Pärnu (Klein y Staudt 2006), Itä Uusimaa (Virkki et al. 2006) y Gdansk (Staudt et al. 2006). Pärnu utilizó los resultados del proyecto SEAREG y su proyecto de seguimiento «La creación de políticas y estrategias de adaptación al cambio climático en la región del mar del mar Báltico» (ASTRA) para tomar decisiones acerca de la construcción de malecones (Schmidt-Thomé 2006). Polonia es una de las primeras naciones de la región del mar Báltico que ha adoptado las hipótesis sobre el cambio climático y la consiguiente subida del nivel del mar en su estrategia costera a largo plazo (comunicación sobre una conferencia de ASTRA por la Oficina Marítima, Gdynia, Polonia). En la actualidad, se está aplicando el planteamiento del Marco y es objeto de ampliación en el proyecto BSR INTERREG IIIB «ASTRA» (véase www.astra-project.org). Asimismo, se está desarrollando y aplicando en zonas costeras de Finlandia, Letonia, Estonia, Lituania, Alemania y Polonia. 


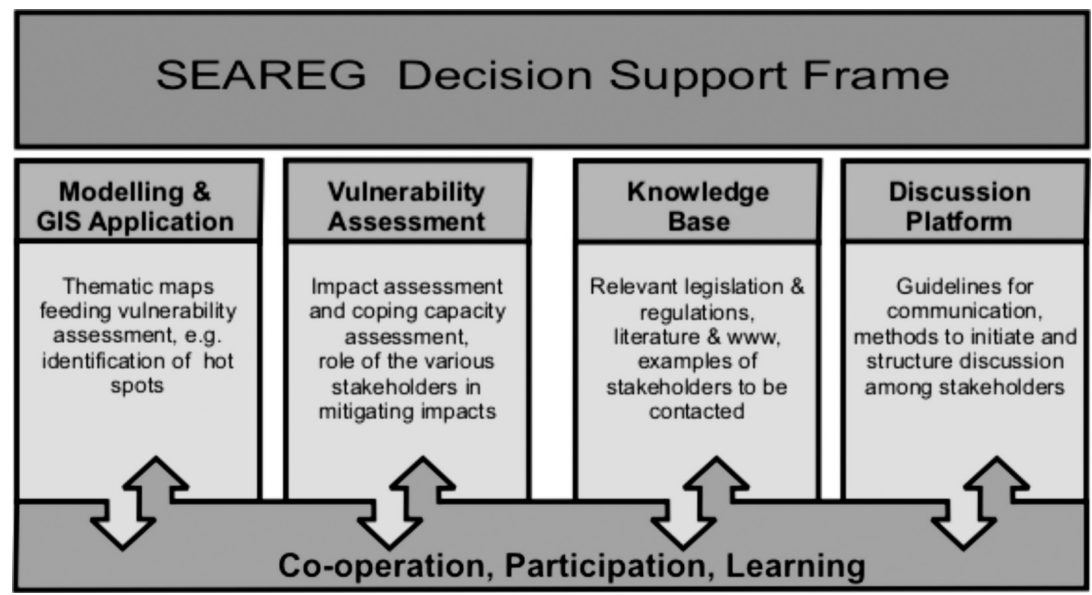

Fuente: Schmidt-Thomé y Peltonen 2006.

\section{Debate}

Los planteamientos anteriores utilizados para la evaluación y la gestión constituyen ejemplos de iniciativas nacionales en algunos países europeos y del impacto de la Comunidad Europea, representada por la Comisión. Muestran el estado actual de nuestros conocimientos y prácticas sobre cómo los encargados de la ordenación territorial y otras partes interesadas pueden abordar la cuestión de los peligros naturales (y, en parte, también del cambio climático) para tratar los riesgos. No obstante, sigue faltando un planteamiento integral que contemple todos los peligros naturales que pueden afectar en potencia a cualquier zona. En la actualidad, la mayoría de las iniciativas y directrices se centran en los peligros más destacados (o los que han tenido lugar más recientemente), según queda de manifiesto en la próxima directiva europea sobre la gestión del riesgo de inundaciones. En la mayoría de los países en los que se observan los peligros naturales en la ordenación territorial, la atención se centra sobre todo en las inundaciones debido al interés del público por los sucesos recientes. No son frecuentes las estrategias integradas sobre múltiples peligros ni se presta la debida atención a los principios de la gestión pública, aunque el ejemplo más completo de evaluación exhaustiva de múltiples peligros se encuentre probablemente en Massachusetts (Schmidt-Thomé 2006, Fleischhauer et al. 2006). Los recientes sucesos extremos que han desencadenado desastres naturales, así como interacciones de peligros, demuestran que una estrategia integral que tenga en cuenta todos los peligros potenciales sería más adecuada (Schmidt-Thomé 2006). Por lo tanto, el proyecto ESPON sobre Peligros ha señalado, en primer lugar, todos los peligros relevantes para la ordenación territorial que pueden afectar al territorio europeo y ha compilado datos pertinentes para representar los peligros en forma de mapa (Fleischhauer 2006, Schmidt-Thomé y Kallio 2006). Pese a los defectos naturales de una estrategia tan innovadora, el valor de los resultados reside en la metodología de examinar primero las fuentes potenciales de peligros y, a continuación, elaborar mapas de peligros individuales para, finalmente, integrarlos en mapas de riesgos y peligros agregados. Los siguientes pasos consistirán en debatir cómo se pueden analizar los riesgos (Schmidt-Thomé 2006). De este modo, también resulta necesario definir de forma inequívoca los peligros 
naturales y diferenciarlos entre sí y entre otros procesos naturales (Schmidt-Thomé 2006). Como se ha mencionado anteriormente, el proceso de agregación de los peligros es muy complejo debido a que no todos los peligros tienen las mismas repercusiones en el territorio $\mathrm{y}$ a que tienen distintas duraciones y recurrencias. Por lo otro lado, a duras penas se pueden armonizar las diversas dimensiones de la vulnerabilidad porque algunas dependen de los peligros y otras no. En concreto, la pregunta de qué parámetros (por ejemplo, frecuencia, magnitud, densidad de la población, posibles daños, etc.) deben constituir la base para las zonas de riesgo y, por ende, la base para delimitar las zonas de uso restringido del suelo muestra simplemente la naturaleza normativa de la evaluación y la gestión de los riesgos. Depende del nivel de riesgo que la sociedad esté dispuesta a aceptar.

El método de ponderación elegido en el proyecto ESPON sobre Peligros para agregar los peligros según su importancia desde el punto de vista europeo ha funcionado bien y está aceptado por la comunidad científica. No obstante, también dio lugar a resultados poco satisfactorios en algunos casos. Por ejemplo, Italia parece ser menos peligrosa que otros países según el mapa de peligros agregados. Uno de los motivos es que los peligros que son muy relevantes para Italia no lo son tanto para otros países de Europa, por lo que han sido ponderados como menos importantes (por ejemplo, volcanes, tsunamis). Por consiguiente, debe subrayarse que cada vez que se cambia el ámbito o la escala de la agregación, la ponderación debe volver a emprenderse desde el principio.

Al debatir las posibles repercusiones del cambio climático en los peligros naturales, resulta fundamental distinguir entre los peligros que están realmente afectados por el cambio climático y los que no lo están. Con frecuencia, no se conocen bien esas diferencias, ni las interacciones potenciales entre los distintos peligros en un clima cambiante, pero son objeto de otras investigaciones actuales (Schmidt-Thomé 2006, véase también, por ejemplo, www.astra- project.org).

\section{Conclusiones}

A modo de conclusión, puede afirmarse que los proyectos de cartografía de peligros naturales son útiles para obtener una visión general. Durante la fase de puesta en práctica y desarrollo de los mapas de peligros individuales y agregados, el equipo de proyectos constató los pocos conocimientos que había respecto al alcance y a la magnitud de los peligros desde el punto de vista europeo. Muchos investigadores, y también la Comisión Europea, contaban con un conocimiento local excelente sobre los peligros, pero muy pocos tenían una visión panorámica de toda Europa y, cuando la tenían, en la mayoría de los casos era sobre un peligro concreto y no sobre múltiples peligros. Además, se precisa mucha más investigación para comprender mejor las distintas dimensiones de la vulnerabilidad (es decir, las que no están determinadas por las estructuras físicas, como la vulnerabilidad de los marcos institucionales, grupos sociales, etc.). Por lo tanto, este tipo de estudios puede contribuir a aumentar la concienciación sobre el tema, lo cual puede llevar a planteamientos más integrados y a una estrategia europea de respuesta a los peligros naturales adaptada al perfil de peligros de las distintas regiones del continente. Sería idóneo que se observaran más los peligros individuales y los múltiples en las estrategias de ordenación territorial. Parece que esas iniciativas reciben más apoyo de la Comisión Europea a través del Fondo Europeo de Desarrollo Regional. Asimismo, el $7^{\circ}$ programa marco de investigación de la UE ha prestado especial atención a este ámbito de la investigación.

El presente artículo ha esbozado únicamente las primeras iniciativas y las estrategias actuales del papel que puede desempeñar la ordenación territorial para que el entorno vital 
sea un lugar más seguro para los seres humanos. Es importante seguir evaluando, desarrollando y respaldando con políticas el potencial que encierra la ordenación territorial en la mitigación de riesgos y peligros, sobre todo ante el cambio climático, y los retos resultantes para el desarrollo territorial.

\section{Bibliografía}

BÄRRING, L. Y PERSSON, G. (2006): Influence of climate change on natural hazards in Europe. In: Schmidt-Thomé (ed.) 2006. Natural and Technological Hazards and Risks in European Regions, Geological Survey of Finland, Special Paper 42, Espoo, pp. 93-107.

BULKELEY, H. (2006): A changing climate for planning. En: Planning theory \& practice, Vol. 7 , N. ${ }^{\circ}$ 2, pp. 203-213.

EGLI, T. (2000): Gefahrenkarten für die Bauvorsorge und Notfallplanung. En: Umweltbundesamt (2000): Workshop Vorbeugender Hochwasserschutz auf kommunaler Ebene, 13. und 14. Dezember 2000, im Institut für ökologische Raumentwicklung e. V., Dresden. Berlin, Dresden (UBA/ IÖR) 2000. S. 78-88. Disponible en: http://www.umweltdaten.de/rup/hochwasser-workshop/ praesentation/7- vortrag_egli.pdf (23.05.2005).

EMERGENCY DISASTERS DATABASE (Em-Dat) (2006): Trends and Relationships for the period 1900-2005. Disponible en: http://www.em-dat.net/disasters/trends.htm, visitado el 02.08.2006.

ESDP. 1999. ESDP - European Spatial Development Perspective. Towards a balanced and sustainable development of the Union territory. Adoptado en mayo de 1999 en el Consejo informal en Postdam de ministros responsables de la ordenación territorial. Disponible en: http://europa.eu/scadplus/leg/en/lvb/g24401.htm, visited 16.08.2006. European Commission. 2006. Proposal for a Council decision on Community strategic guidelines on cohesion $\{$ SEC(2006) 929\}. Brussels, 65p. disponible en: http://ec.europa.eu/regional_policy/sources/docoffic/2007/ osc/com_2006_0386_en.pd f, visited 17.08.2006.

FEDERAL OFFICE FOR SPATIAL DEVELOPMENT (in cooperation with: Federal Office for Water and Geology, Swiss Agency for the Environment, Forests, and Landscape) (2006): Recommendation - Spatial Planning and Natural Hazards. Reference: www.are.ch. Disponible en: http://www.bwg.admin.ch/themen/natur/e/pdf/Naturgefahren_e.pdf, visitado el 21.06.2006.

FLEISCHHAUER, M. (2006): Spatial relevance of natural and technological hazards. En: SchmidtThomé (ed.) 2006. Natural and Technological Hazards and Risks in European Regions, Geological Survey of Finland, Special Paper 42, Espoo, 7-15. Fleischhauer, M./Greiving, S./Wanczura, S. (Eds. 2006). Spatial Planning and Natural Hazards in Europe. Dortmunder Vertrieb für Bau- und Planungsliteratur. Dortmund, 2006.

GREIVING, S. (2002): Räumliche Planung und Risiko, Gerling Academy Press, Munich, 2002.

GREIVING, S. (2005): Concepts and indicators for measuring institutional vulnerability, Proceedings of the 2nd meeting of the UN expert group on vulnerability. UN-EHS. Bonn.

GREIVING, S. (2006): What are the really needs of spatial planning for dealing with natural hazards? En: Fleischhauer, M./Greiving, S./Wanczura, S. (Eds. 2006). Spatial Planning and Natural Hazards in Europe. Dortmunder Vertrieb für Bau- und Planungsliteratur. Dortmund 2006.

GREIVING, S. (2006a): «Retreat»-Options and hindrances for a flood risk mitigation by means of spatial planning». Proceedings of the Conference «Communities living with flood risk in a changing climate». Cambridge, R.U.

GREIVING, S. \& FLEISCHHAUER, M. (2006): Spatial planning response towards natural and technological hazards. En: Schmidt-Thomé, P. (ed.): Natural and Technological Hazards and Risks Affecting the Spatial Development of European Regions. Geological Survey of Finland. Special Paper 42. Espoo.

GREIVING, S. (2006b): Integrated risk assessment of multi-hazards: A new methodology. Natural and Technological Hazards and Risks in European Regions. Geological Survey of Finland Special Paper 42, pp. 75-81.

INTERNATIONAL RISK GOVERNANCE COUNCIL (2005): Basic concepts of risk characterisation and risk governance, Ginebra 2005. 
INTERNATIONAL STRATEGY FOR DISASTER REDUCTION (Ed. 2005): Hyogo Framework of Action.

JARVA, J. \& VIRKKI, H. (2006): Dealing with hazards: Practice in the Finnish spatial planning system. En: Fleischhauer, M., Greiving, S. \& Wanczura, S. (editores). 2006. Natural hazards and planning in Europe, Dortmund, pp. 19-36.

KLEIN, J. y STAUDT, M. (2006): Evaluation of future sea level rise impacts in Pärnu / Estonia. En: Schmidt-Thome, P. (editor): Sea level Changes Affecting the Spatial Development of the Baltic Sea Region. Geological Survey of Finland, Special Paper 41, Espoo, pp. 71-81.

KLINKE, R. y RENN, O. (2002): A New Approach to Risk Evaluation and Management: Risk-Based, Precaution-Based and Discourse-Based Strategies, Risk Analysis Vol. 22 2002, pp. 1071-1094.

LEVET, R. (2006): Planning for climate change: Reality time. In: Planning theory \& practice, Vol. 7, N. ${ }^{\circ}$ 2, pp. 214-217.

MARTTILA, V., GRANHOLM, H., LAANIKARI, J., YRJÖLÄ, T., AALTO, A., HEIKINHEIMO, P., HONKATUKI, J., JÄRVINEN, H., LISKI, J., MERIVIRTA, R. y PAUNIO, M. (eds.). (2005): Finland's National Strategy for Adaptation to Climate Change. Ministry of Agriculture and Forestry, Helsinki 280 p. Disponible en: http://www.mmm.fi/sopeutumisstrategia/, visitado el 08.08.2006.

MUNICH REINSURANCE COMPANY (2004): Great Natural Catastrophes, Topics geo 1/2004: Annual Review of Natural Catastrophes 2003. Munich. 60 p.

OLFERT, A., GREIVING, S. \& BATISTA, M. J. (2006): Regional multi-risk review, hazard weighting and spatial planning response to risk - results from European case studies. En: Schmidt-Thomé, P. (ed.) 2006. Natural and Technological Hazards and Risks in European Regions. Geological Survey of Finland Special Paper 42, 125-151. Peltonen, L., Haanpää, S. and Lehtonen, S. 2005. The challenge of climate change adaptation in urban planning. FINADAPT Working Paper 13, Finnish Environment Institute Mimeographs 343, Helsinki, 44 p.

ROBINSON, P. (2006): Canadian municipal response to climate change: Measurable progress and persistent challenges for planners. In: Planning theory \& practice, Vol. 7, No. 2 pp. 218-222.

SCHMIDT-THOMÉ, P. (ed.) (2005): The Spatial Effects and Management of Natural and Technological Hazards in Europe - final report of the European Spatial Planning and Observation Network (ESPON) project 1.3.1. Geological Survey of Finland. Espoo, 197 p.

SCHMIDT-THOME, P. (ed.) (2006): Sea level Changes Affecting the Spatial Development of the Baltic Sea Region, Geological Survey of Finland, Special Paper 41, Espoo, 154 p.

SCHMIDT-THOMÉ (ed.) (2006): (2) Natural and Technological Hazards and Risks in European Regions, Special Paper 42, Geological Survey of Finland, Espoo, 167p. Schmidt-Thomé, P. 2006. Integration of natural hazards, risk and climate change into spatial planning practices. Tesis académica n. ${ }^{\circ} 193$ de la Universidad de Helsinki. Geological Survey of Finland, 31+107 p.

SCHMIDT-THOMÉ, P. y KALLIO, H. (2006): Natural and Technological Hazard Maps of Europe. In: Schmidt-Thomé, P. (ed.) 2006. Natural and Technological Hazards and Risks in European Regions. Geological Survey of Finland Special Paper 42, 17-63. Schmidt-Thomé, P., Klein, J. y Schmidt-Thomé, K. 2006. (2) Environmental Hazards and Risk Management - Thematic Study of INTERREG and ESPON activities.

Informe ESPON-INTERACT. Publicación en internet disponible en www.interact-eu.net y www. gtk.fi/projects/espon, visitado el 06.07.2006.

SCHMIDT-THOMÉ, P., JARVA, J. HAANPÄÄ, S. LEHTONEN, S., PELTONEN, L. (2006): A country without hazards? En: Eskelinen, H. \& Hirvonen, T. Positioning Finland in a European Space. Ministerio de Medio Ambiente, Ministerio del Interior. Helsinki, pp. 121-135. SchmidtThomé, P. y Peltonen, L. 2006. Sea level Change Assessment in the Baltic Sea Region and Spatial Planning Responses. En: Schmidt-Thomé, P. (ed.) 2006. Sea level Changes Affecting the Spatial Development of the Baltic Sea Region, Geological Survey of Finland, Special Paper 41, Espoo, 7-17.

SCHMIDT-THOMÉ, P. y SCHMIDT-THOMÉ, K. (2007): Natural hazards and climate change: stakeholder communication and decision-making processes: an analysis of the outcomes of the 2006 Davos conference on Disaster reduction. En: Management of Environmental Quality 18 (3), pp. 329-339. 
SLOVIC, P. (1999): Trust, Emotion, Sex, Politics, and Science: Surveying the Risk- Assessment Battlefield. Risk Analysis, Vol. 19, N. ${ }^{\circ}$ 4, 1999.

STAUDT M., KORDALSKI Z. y ZMUDA J. (2006): Assessment of modelled sea level rise impacts in the Gdańsk region, Poland. En: Schmidt-Thome, P. (editor): Sea level Changes Affecting the Spatial Development of the Baltic Sea Region. Geological Survey of Finland, Special Paper 41, Espoo, pp. 121-130.

TERRITORIAL AGENDA FOR EUROPEAN UNION (2007): Borrador a ser presentado a los Ministros responsables del desarrollo territorial con occasion de la reunión ministerial informal sobre Cohesión Territorial a ser celebrada en Leipzig el 25 de mayo de 2007. Disponible en: www.territorial-agenda.eu.

THE NEW NATIONAL CLIMATE CHANGE PROGRAM (2005): http://www.bmu.de/files/english/ climate/downloads/application/pdf/klimaschutzprogramm_2005_en .pdf, visited 22.02.07.

THE TERRITORIAL STATE AND PERSPECTIVES OF THE EUROPEAN UNION (2007): Borrador. Documento de referencia para la Agenda Territorial de la Unión Europea. Disponible en: www.territorial-agenda.eu.

UNITED KINGDOM (2006): Climate Change - The UK Programme 2006. Secretary of State for the Environment, Food and Rural Affairs. CM6764 SE/2006/43. 202 p. Disponible en: http://www. defra.gov.uk/environment/climatechange/uk/ukccp/pdf/ukccp06-all.pdf, visitado el 07.08.2006.

VIRKKI, H., KALLIO, H. y ORENIUS, O. (2006): Sea Level Rise and Flood Risk Assessment in ItäUusimaa. En: Schmidt-Thome, P. (editor): Sea level Changes Affecting the Spatial Development of the Baltic Sea Region. Geological Survey of Finland, Special Paper 41, Espoo, pp. 95-106.

VRIES, DE, J. (2006): Climate change and spatial planning below sea-level: Water, water and more water. En: Planning theory \& practice, Vol. 7, N. ${ }^{\circ} 2$, pp. 223-226.

WBGU. German Advisory Council on Global Change (1999): World in Transition: Strategies for Managing Global Environmental Risks. Springer Press, Berlin. 
